\title{
Comparing Perceived Formal and Informal Learning in Face-to-Face versus Online Environments
}

\author{
Ariella Levenberg and Avner Caspi \\ Open University of Israel, Raanana, Israel
}

\author{
alevenberg@gmail.com; avnerca@openu.ac.il
}

\begin{abstract}
Two hundred and thirty-nine elementary school teachers reported their perceived learning (cognitive and affective aspects) in four learning environments: Formal - face-to-face (teachers' professional development courses), Informal - face-to-face (teachers' lounge), Formal - online (online teacher professional development courses), and Informal - online (teachers' online forum). We found that perceived learning in formal learning environments was higher than in informal learning environments. The effect of communication media was also significant; teachers who communicated online reported higher perceived learning than teachers who communicated face-toface. The interaction between formality and communication media was also significant. In the informal environments, online learners perceived their learning to be higher than face-to-face learners, whereas in formal learning environments there was no such difference. These results revealed the importance of the medium in different learning environments.
\end{abstract}

Keywords: perceived learning, formal learning, informal learning, online learning, face to face learning, teachers.

\section{Introduction}

The learning and professional development of teachers has increasingly become the focus of interest for policy and decision makers (Zuzovsky \& Donitsa-Schmidt, 2004). Much effort has therefore been devoted to improving teachers' continuing learning, with varying degrees of success. Methods of facilitating teachers' learning may be classified broadly by medium and by level of formality. Two major media used for teachers' learning are traditional face-to-face (f2f) lectures and computer-mediated or online courses. Teachers' professional development acquired online has received a lot of scientific attention in recent years (Blanchard, Grable, \& Sharp, 2009; Lloyd \& Duncan-Howell, 2010; Rice \& Dawley, 2009). The concept of informal learning is blurred in the literature, though multiple

Material published as part of this publication, either on-line or in print, is copyrighted by the Informing Science Institute. Permission to make digital or paper copy of part or all of these works for personal or classroom use is granted without fee provided that the copies are not made or distributed for profit or commercial advantage AND that copies 1) bear this notice in full and 2) give the full citation on the first page. It is permissible to abstract these works so long as credit is given. To copy in all other cases or to republish or to post on a server or to redistribute to lists requires specific permission and payment of a fee. Contact Publisher@InformingScience.org to request redistribution permission. references to this concept exist (Billett, 2002; Colley, Hodkinson, \& Malcolm, 2003; Hoekstra, 2007; Marsick \& Watkins, 2001; Straka, 2002). Although informal workplace learning has attracted considerable attention in the literature (Skule, 2004), less is known about informal learning of teachers. The present study aimed at revealing the influence of the medium and level of formality on

\section{Editor: Alex Koohang}

An earlier, shorter version of this paper was presented at the Chais conference 2010, in Raanana, Israel, and included in Y. Eshet-Alkalai, A. Caspi, S. Eden, N. Geri, \& Y. Yair (Eds.), Proceedings of the Chais conference on instructional technologies research 2010: Learning in the technological era. Raanana: The Open University of Israel. http://www.openu.ac.il/research center eng/conferences.html 
teachers' learning. We begin by defining formal and informal learning. Then we will briefly present our dependent variable - perceived learning, which was used to compare teachers' learning in the different learning environments.

\section{Formal and Informal Learning}

Operational definitions that differentiate formal and informal learning are based on the proposals made by Livingstone (2001), Eraut (2000) and Beckett and Hager (2000). We will not define learning here, and the reader may find a useful discussion in Alexander, Schallert and Reynolds (2009). However, for the purposes of the current study, we adopt T. Anderson's (2008) definition of online learning, which suggested it is "the use of the Internet to access learning materials; to interact with the content, instructor, and other learners; and to obtain support during the learning process, in order to acquire knowledge, to construct personal meaning, and to grow from the learning experience" (p.5).

Formal learning is learning supported by an educational or training institution, structured (in terms of learning objectives, learning schedule, or learning support), controlled by a teacher or a guide, resulting in a certificate, or by accreditation in the form of recognition of that training or in receiving points towards a salary reward. Formal learning is not necessarily made intentionally by learners. Informal learning is not supported by an educational or training institution. It is controlled primarily by the learner, does not have a predefined structured curriculum, and does not result in receiving a certificate. Informal learning can also be achieved through every-day or social activities, nevertheless the learner needs to consciously recognize, even if in retrospect, that (s)he was involved in learning.

The above two definitions suggest seeing the two ways of achieving learning as very different, although it is clear that in practice there may be merging of some criteria, and the distinctions may be less obvious. Our definitions rely on two axes: structural (e.g., institution, schedule, accreditation) and psychological (e.g., intention, control). By doing so, we try to combine earlier definitions that emphasized different distinctions between the two types of learning (Beckett \& Hager, 2000; Eraut, 2000, 2004; Livingstone, 2001). It is noted that other approaches attempting to differentiate formal and informal learning exist (for review see: Hager \& Halliday, 2006).

\section{Perception of Learning}

The perception that learning has occurred may depend on the conception one holds of what learning is (Boulton-Lewis, Marton, Lewis, \& Wills, 2000; Cano, 2005). A phenomenological perspective (Martin \& Ramsden, 1987; Marton, Dall'Alba, \& Beaty, 1993; Marton \& Säljö, 1976; Säljö, 1979) identified six different conceptions, which consider learning as: (1) increasing one's knowledge, (2) memorizing and reproducing, (3) applying, (4) understanding, (5) seeing something in a different way, and (6) changing as a person. These conceptions reflect different dimen-

sions of the learning process. An individual who believes that one of these dimensions of learning was achieved, particularly the dimension that matches his or her own conception of learning, will infer that learning has occurred. Phenomenographic studies resulted in defining the learning experience as a cognitive experience. It is thus suggested that when an individual feels that a change has occurred, that new knowledge has been acquired, or that some new understanding has been achieved, he or she relies on the cognitive source of the learning experience (Caspi \& Blau, 2008).

However, learning is usually experienced or perceived as a complex event, which may rely on more than the cognitive experience. Human cognitive efforts are accompanied by a variety of metacognitive experiences, which provide experiential information. This information may be recalled when students are asked to assess their learning. The experiential information that operates 
in concert with the cognitive experience of learning constructs the affective source of the learning experience. Studies have shown that this affective source includes emotions, interests, opinions, attitudes, and values felt during the learning process (L. Anderson \& Krathwohl, 2001; Krathwohl, Bloom, \& Masia, 1964; Rovai, Wighting, Baker, \& Grooms, 2009).

Caspi and Blau (2008) suggested that, in retrieving the experience of learning, one may rely on either the cognitive source or the affective source or both. Emotional experiences may be the learning itself but can also serve as an indirect route that forms the experience that learning, in the sense of cognitive change, occurs.

Since informal learning is managed primarily by the learner, has a non-structured curriculum, and does not terminate with summative evaluation, there is no way to assess it other than by tracing the perception of learning. While it is relatively easy to examine learners' achievements in formal learning, it is impossible to do so in informal learning. However, examining the perception of learning does not depend on the extent of formality of the learning, making this variable highly suitable for a comparison between the two learning environments. Moreover, the perception of learning focuses on the experiential aspects of learning. As such the present study may provide rich and previously undocumented information.

In this research study, we compared perceptions of formal and informal learning that occurred online and face-to-face. Differences between learning environments (online vs. face-to-face) may influence learners' achievements and satisfaction (Allen, Bourhis, Burrell, \& Mabry, 2002; Heckman \& Annabi, 2005; Jahng, Krug, \& Zhang, 2007; Russell, 1999). Recent meta-analysis (Means, Toyama, Murphy, Bakia, \& Jones, 2009) found more than a thousand empirical research studies concerning online learning. They observed that online learning has been reported to have better learning results than face-to-face learning in terms of self-reflection, self-regulation, and self-monitoring. To the best of our knowledge, few comparisons of the two environments in terms of perception of learning have been done, and none at all in informal learning environments.

\section{Research Goals and Hypotheses}

The purpose of this study was to compare teachers' perception of learning in formal as well as informal learning environments, both online and face-to-face. Crossing the two levels of formality by the two media utilized, we compared perceived learning in four environments. Table 1 presents the four environments. The face-to-face informal learning environment was selected following Ben-Peretz and Schonmann's (2000) documentation of the Israeli teachers' lounge. They found that the teachers' lounge is the physical space in schools for teachers to gain professional knowledge in informal ways.

Table 1: Classification of the four learning environments

\begin{tabular}{lll}
\cline { 2 - 3 } & Face-to-face & Online \\
\hline Formal learning & $\begin{array}{l}\text { Teacher professional development } \\
\text { courses }\end{array}$ & $\begin{array}{l}\text { Teacher online professional } \\
\text { development courses }\end{array}$ \\
\hline Informal learning & Teachers' lounge & Teachers' online forum \\
\hline
\end{tabular}

The perception of learning includes cognitive and affective aspects (Caspi \& Blau, 2008; see also Rovai et al., 2009). The influence of the two independent variables on these two aspects of perception of learning may differ. We hypothesized that:

(1) Informal learning will be perceived to be higher than formal learning. The main reason is that in informal learning, the process is controlled primarily by the learners and the 
learners' conscious intention to learn. Thus, learners may acknowledge their effort to learn more in informal than in formal learning. The first is characterized as less controlled and, perhaps, has lower accountability qualities from the learners' point of view. We predicted that this pattern would be found for both the cognitive and the affective aspects of perceived learning.

(2) If learners feel that learning had occurred, the medium may have no impact. Thus, in terms of the cognitive aspect of learning, we did not expect to find a difference between face-to-face and online learning. However, it has been repeatedly found that students prefer face-to-face over online learning, and they are more satisfied with the traditional delivery method (Allen et al., 2002; Bernard et al., 2004). We therefore expected a higher perception of learning in terms of the affective aspect in face-to-face learning.

(3) We expected an interaction between media and formality. Perception of learning in online informal learning will be higher than in face-to-face informal learning since the attributes of the online medium are particularly suitable for self-directed learning, a core feature of informal learning (Candy, 2004). A reverse pattern was predicted in formal learning. Perceived learning in a face-to-face environment will be higher than in an online environment, due to the mental models of teachers - that learning processes, including the teaching aspects, exist only in formal learning (Olson \& Bruner, 1996).

\section{Method}

\section{Participants}

Two hundred and thirty-nine elementary school teachers completed a questionnaire. Since male teachers are rare, we included only females in this study. Eighty-one teachers responded to questionnaires posted in the teachers' online forum for elementary education ${ }^{1}$ (informal online environment); 49 teachers answered the questionnaires that were released online in various professional development courses of the Ministry of Education (formal online environment); 53 teachers responded to questionnaires distributed in professional development course centers of the Ministry of Education (formal face-to-face environment); and 56 teachers from six state schools answered the teachers' lounge questionnaires (informal face-to-face environment).

\section{Research Tools and Procedure}

Questionnaires were delivered either online or by paper-and-pencil forms. Previous studies showed that the differences between online and paper-and-pencil forms for the same questionnaire are negligible (Boyer, Olson, Calantone, \& Jackson, 2002; Denscombe, 2006; Ferrando \& Lornzo-Seva, 2005; Leung \& Kember, 2005; Lucia, Herrmann, \& Killias, 2007). We used Blau and Caspi's (2008) questionnaire with minor changes made to adapt the questions to the current population. This questionnaire consists of three aspects of perceived learning. The first is the cognitive aspect, and the two others relate to the affective aspect: emotional aspect and social aspect. Initial factor analysis with Varimax rotation revealed four factors: Cognitive (Cronbach's alpha $=.88$ ), positive-emotion (Cronbach's alpha $=.88$ ), negative-emotion (Cronbach's alpha $=$ .85 ) and social (Cronbach's alpha $=.83$ ). We adapted the questionnaire for each learning environment. Thus for example, the item "I enjoy learning in the professional development course" was presented as "I enjoy learning in the online professional development course", "I enjoy learn-

http://www.orianit.org/fmorim/forum/forum topics.asp?fid $=1^{1}$ Teachers' forum in elementary education: 
ing in the teachers' lounge", or "I enjoy learning in the teachers' online forum", depending on the population that received the questionnaire.

\section{Findings}

The following section has two parts. Each part addresses one of the aspects of perceived learning (cognitive and affective), specifying the results according to the hypotheses and providing possible explanations.

\section{Cognitive Aspect}

A main effect was found for formality, $F(1,232)=6.76, \mathrm{p}<.01$, partial $\eta^{2}=.03$. Contrary to our hypothesis, teachers perceived their learning to be higher when it occurred in a formal setting (teacher professional development courses). We found a main effect of communication media, $F$ $(1,232)=38.68, p<.001$, partial $\eta^{2}=.14$. As predicted, online learners perceived their learning higher than face-to-face learners. The interaction between the two variables was also significant, $F(1,232)=19.82, p<.001$, partial $\eta^{2}=.08$. We found a significant difference between informal online learning and informal face-to-face learning $\mathrm{t}(135)=6.96, p<.001$, while no significant difference was found in formal learning between the two communication media. Figure 1 shows these results.

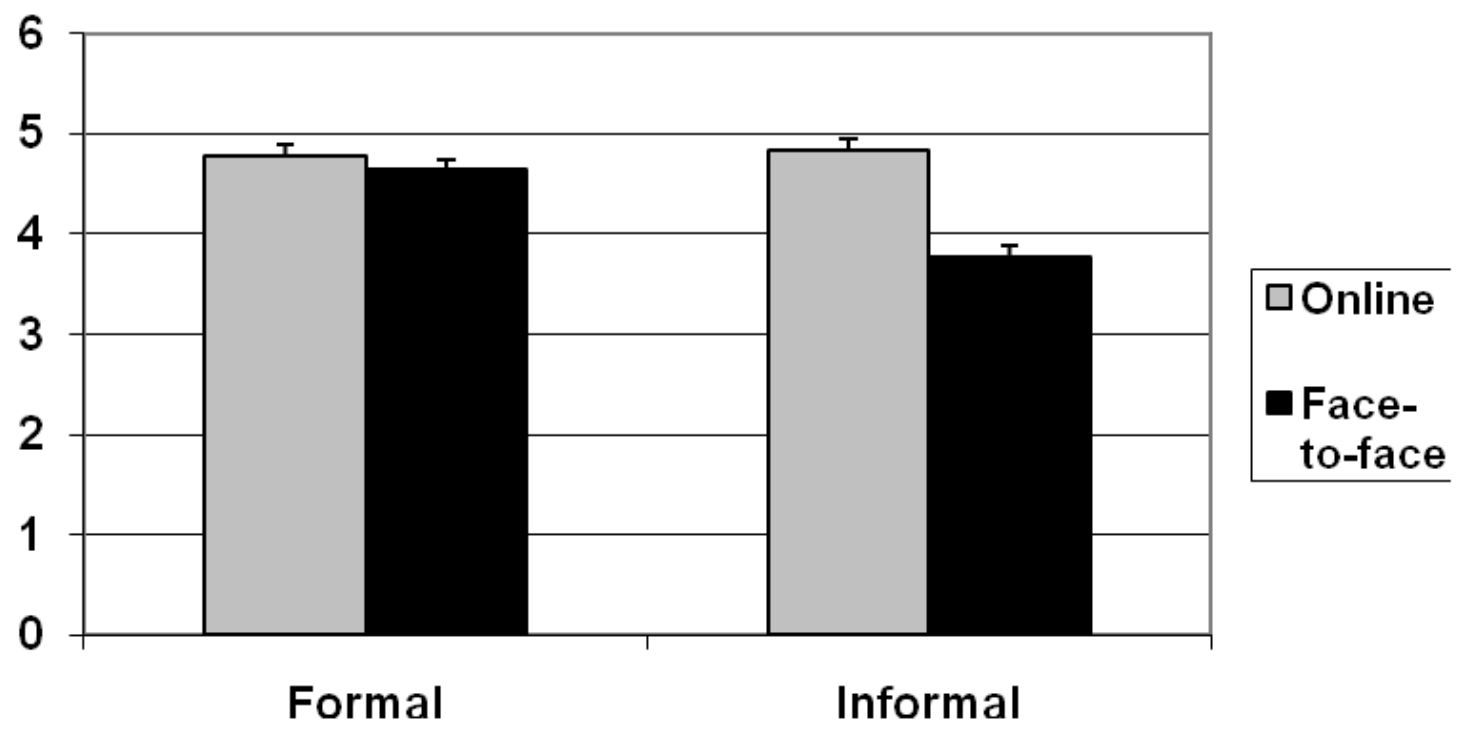

Figure 1. The influence of communication media and formality on the cognitive aspect of perceived learning

\section{Affective Aspect}

\section{Positive emotions}

Contrary to our hypothesis, there was no significant effect of formality, $F(1,232)<1$. However, as predicted, a significant effect was found for communication media, $F(1,232)=24.10, p<.001$, partial $\eta^{2}=.09$. Online learners perceived their learning higher than face-to-face learners, in terms of positive emotions. The interaction between the two variables was also significant, $F$ $(1,232)=6.58, p=.01$, partial $\eta^{2}=.03$. As in the cognitive aspect, perceived informal learning in an online environment was higher than perceived learning in a face-to-face environment, while in 
the formal learning environments this difference was not significant. Figure 2 presents these results.

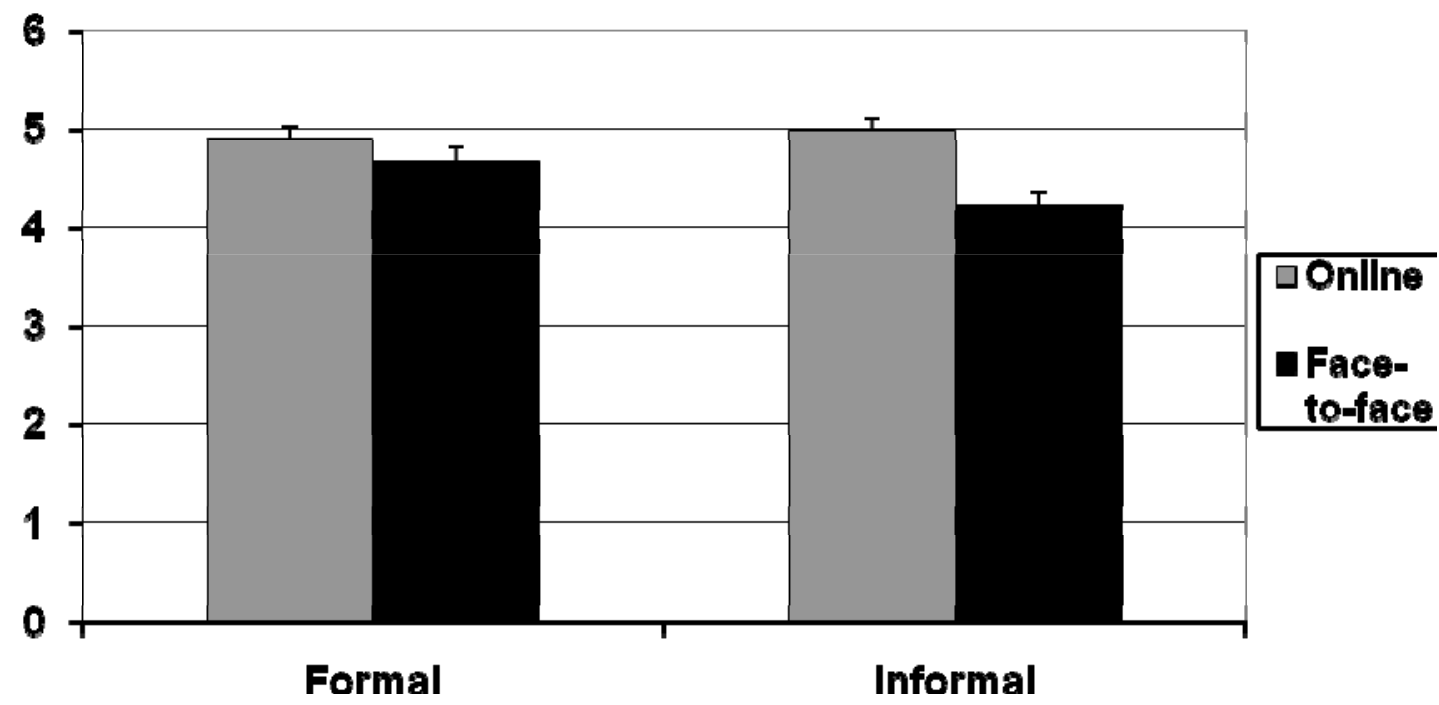

Figure 2. The influence of communication media and formality on the positive emotions of perceived learning

\section{Negative emotions}

No main effect was found for formality, $F(1,232)=2.23, p>.13$, and for communication media, $F(1,232)<1$. The interaction between the two variables was significant, $F(1,232)=6.59, p=.005$, partial $\eta^{2}=.03$. Further analysis revealed that in informal learning face-to-face, learners felt more negative emotion than online learners, $t(135)=3.60, p<.001$, while in formal learning a reverse pattern was found, $t(100)=2.43, p<.02$. A possible explanation might be that while the context of formal face-to face learning is common and familiar to teachers, online learning may be more

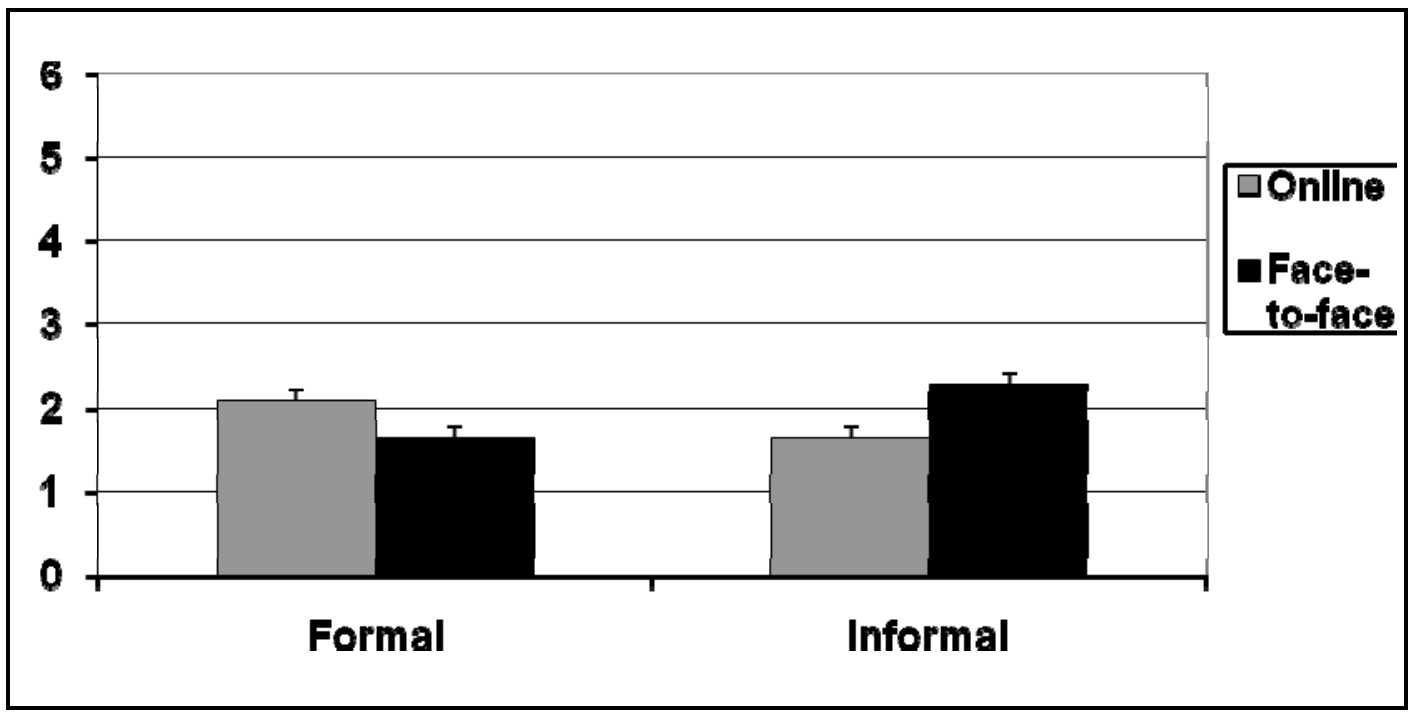

Figure 3. The influence of communication media and formality on the negative emotions of perceived learning 
threatening or even intimidating, especially because of the actual use of communication technologies. Figure 3 depicts the interaction between formality and communication media.

\section{Social aspect}

Only the main effect of formality was significant, $F(1,232)=14.63, p<.001$, partial $\eta^{2}=.06$. In contrast to the above variables in which this effect was found, in formal learning, the social aspect of perceived learning (Mean: 3.89, SD: 0.90) was lower than in informal learning (Mean: 4.13, SD: 1.19). The effect of communication media and the interaction were not significant (both $F(1,232)$ 's $<1)$. It is possible that the amount of social interaction was limited by the nature of formal learning, especially by its rigid discipline, restricted befriending time, and the inflexible curriculum that decreases the opportunities for developing social relationships. In informal learning there are fuzzy boundaries that make more room for social interactions (Freeth \& Reeves, 2004; Jarvis, 1987).

\section{Discussion and Conclusions}

We compared different aspects of teachers' perceived learning in four learning environments: formal versus informal environments, online and face-to-face. The results of the affective aspect supported our first hypothesis that informal learning will be perceived as higher than formal learning. However, the results of the cognitive aspect were in the opposite direction: Learning was perceived to be higher in the formal environment. These results reveal the dissociation between the two aspects of perceived learning. Furthermore, they disclose the influence of the environment on the perception of learning. We suggest that when in a formal setting one may adopt a specific view of what learning is, which might internalize the hierarchical and highly structured type of learning. This may be in line with the mental models of teachers, that learning processes appear only in formal learning (Olson \& Bruner, 1996). This view may regard social interaction as "residual" learning, emphasizing content, authority and accountability over inquiry, trial-anderror, and construction of knowledge. Learners in informal settings may adopt the other view, which highlights learning as a social event.

As opposed to previous reports, we found that online learning scored higher than face-to-face learning in both the cognitive and the affective aspects. These results also disprove our second prediction, that when learners feel that learning has occurred, the medium may have no impact on the cognitive aspect, while a face-to-face environment is preferred by learners. It is noted that the environments in this study may be differentiated not merely by the two independent variables in which we were interested, but by many other variables we cannot control. Thus, further studies are needed before concluding that online environments are better than face-to-face environments.

In accord with our hypothesis, formality and communication media interacted in a meaningful way. In general, the medium makes a difference in perceived learning in informal environments but not in formal ones. Perhaps the perception of informal environments as a learning place was enhanced by the online medium. It is noted that the teachers' lounge has different goals, not necessarily related directly to learning, whereas the online forum, although affording many activities, may have a stronger linkage with learning.

Using perceived learning as a dependent variable allows comparisons between formal and informal learning. Clearly, these comparisons are limited and open merely a narrow window into the processes taking place. The results shed light on conception and perception of learning, exposing the interdependence between the environments and the perception that learning has occurred.

The findings of our study give rise to new questions regarding perceived learning in formal and informal learning environments, online and face-to-face, contributing to the conceptualization of teachers' learning framework in different settings. Specifically, the findings can be used to recon- 
sider the design and structure of teachers' workplace environments in order to further encourage informal learning as well as adding informal components to professional development programs, online and offline. Additionally, taking into account different aspects of learning may help designing learning environments that allow broader and deeper experiences.

\section{References}

Alexander, P. A., Schallert, D. L., \& Reynolds, R. E. (2009). What is learning anyway? A topographical perspective considered. Educational Psychologist, 44(3), 176-192.

Allen, M., Bourhis, J., Burrell, N., \& Mabry, E. (2002). Comparing student satisfaction with distance education to traditional classrooms in higher education: A meta-analysis. The American Journal of Distance Education, 16(2), 83-97.

Anderson, L., \& Krathwohl, D. R. (2001). A taxonomy for learning, teaching and assessing: A revision of Bloom's taxonomy of educational objectives. New York: Longman.

Anderson, T. (2008). Teaching in an online learning context. In T. Anderson (Ed.), The theory and practice of online learning (2nd ed.) (pp. 273-326). Athabasca, AB: Athabasca University Press. Available at http://www.aupress.ca/books/Terry Anderson.php

Beckett, D., \& Hager, P. (2000). Making judgments as the basis for workplace learning: Towards an epistemology of practice. International Journal of Lifelong Education, 19(4), 200-311.

Ben-Peretz, M., \& Schonmann, S. (2000). Behind closed doors: Teachers and the role of the teachers' lounge. Albany, NY: State University of New York Press.

Bernard, R. M., Abrami, P. C., Lou, Y., Borokhovski, E., Wade, A., Wozney, L., Wallet, P. A., Fiset, M., \& Huang, B. (2004). How does distance education compare with classroom instruction? A metaanalysis of the empirical literature. Review of Educational Research, 74(3), 379-439.

Billett, S. (2002). Critiquing workplace learning discourses: Participation and continuity at work Studies in the Education of Adults, 34 (1), 56-67. Retrieved $18^{\text {th }}$ July, 2009, from http://www98.griffith.edu.au/dspace/bitstream/10072/6630/1/

Blanchard, M., Grable, L., \& Sharp, J. (2009). Scaffolding technology integration of middle school science and mathematics: Comparing the results of two models of teacher professional development. In I. Gibson et al. (Eds.), Proceedings of Society for Information Technology \& Teacher Education International Conference 2009, (pp. 4015-4019). Chesapeake, VA: AACE.

Blau, I., \& Caspi, A. (2008). Do media richness and visual anonymity influence learning? A comparative study using Skype ${ }^{\mathrm{TM}}$. In Y. Eshet-Alkalai, A. Caspi, \& N. Geri (Eds.), Learning in the Technological Era (pp. 18-24). Raanana, Israel: Open University of Israel. Available at http://telempub.openu.ac.il/users/chais/2008/noon/4_2.pdf

Boulton-Lewis, G. M., Marton, F., Lewis, D. C., \& Wills, L. A. (2000). Learning in formal and informal contexts: Conceptions and strategies of Aboriginal and Torres Strait Islander university students. Learning and Instruction, 10, 393-414.

Boyer, K. K., Olson, J. R., Calantone, R. J., \& Jackson, E. C. (2002). Print versus electronic surveys: A comparison of two data collection methodologies. Journal of Operations Management, 20(4), 357-373.

Candy, P. C. (2004). Linking thinking, self-directed learning in the digital age. [Report.] Department of Education, Science and Training, Australia.

Cano, F. (2005). Consonance and dissonance in students' learning experience. Learning and Instruction, $15,201-223$.

Caspi, A., \& Blau, I. (2008). Social presence in online discussion groups: Testing three conceptions and their relations to perceived learning. Social Psychology of Education, 11, 323-346.

Caspi, A., Chajut, E., Saporta, K., \& Beyth-Marom, R. (2006). The influence of personality on social participation in learning environments. Learning and Individual Differences, 16(2), 129-144. 
Colley, H., Hodkinson, P. \& Malcolm, J. (2003) Informality and formality in learning. London: Learning and Skills Research Centre. Available at www.lsda.org.uk/files/PDF/1492.pdf

Denscombe, M. (2006). Web based questionnaires and the mode effect. An evaluation based on completion rates and data contents of near-identical questionnaires delivered in different modes. Social Science Computer Review, 24(2), 246-254.

Eraut, M. (2000) Non-formal learning, implicit knowledge and tacit knowledge in professional work. In F. Coffield (Ed.), The necessity of informal learning (pp.12-31). Bristol, Policy Press in association with the ESRC Learning Society Programme.

Eraut, M. (2004). Informal learning in the workplace. Studies in Continuing Education, 26(2), 247-273.

Freeth, D., \& Reeves, S. (2004). Learning to work together: Using the presage, process, product (3P) model to highlight decisions and possibilities. Journal of Interprofessional Care, 18(1), 43-56.

Ferrando, P. J., \& Lorenzo-Seva, U. (2005). IRT-related factor analytic procedures for testing the equivalence of paper-and-pencil and internet-administered questionnaires. Psychological Methods, 10(2), 193-205.

Hager, P., \& Halliday, J. (2006). Recovering informal learning: Wisdom, judgement and community. Dordrecht, The Netherlands: Springer.

Heckman, R., \& Annabi, H. (2005). A content analytic comparison of learning processes in online and face-to-face case study discussions. Journal of Computer Mediated Communication, 10(2). Retrieved 12 August, 2008, from http://jcmc.indiana.edu/vol10/issue2/heckman.html

Hoekstra, A. (2007). Experienced teachers' informal learning in the workplace. $\mathrm{PhD}$ dissertation, IVLOS Institute of Education of Utrecht University, Holland. Retrieved July 21, 2008 from http://igiturarchive.library.uu.nl/dissertations/2008-0325-200845/hoekstra.pdf

Jahng, N., Krug, D., \& Zhang, Z. (2007). Student achievement in online distance education compared to face-to-face education. The European Journal of Open and Distance Learning, 2007-I. Retrieved July 21, 2009 from http://www.eurodl.org/materials/contrib/2007/Jahng_Krug_Zhang.htm

Jarvis, P. (1987) (Ed.) Twentieth century thinkers in adult education. London: Croom Helm.

Krathwohl, D. R., Bloom, B. S., \& Masia, B. B. (1964). Taxonomy of educational objectives: The classification of educational goals. Handbook II: Affective domain. New York: David McKay.

Leung, D. Y. P. \& Kember, D. (2005) Comparability of data gathered from evaluation questionnaires on paper and through the internet. Research in Higher Education 46(5), 571-591.

Livingstone, D.W. (2001). Adults' informal learning: Definitions, findings, gaps and future research. NALL Working Paper 21-2001. Retrieved July 18, 2008 from https://tspace.library.utoronto.ca/retrieve/4484/21adultsinformallearning.pdf

Lloyd, M. M., \& Duncan Howell, J. (2009). Changing the metaphor: The potential of online communities in teacher professional development. In O. Lindberg, \& A. Olofsson (Eds.), Online learning communities and teacher professional development: Methods for improved education delivery (pp. 60-76). Hershey, PA: Information Science (IGI Global).

Lucia, S., Herrmann, L., \& Killias, M. (2007). How important are interview methods and questionnaire designs in research on self-reported juvenile delinquency? An experimental comparison of Internet vs. paper-and-pencil questionnaires and different definitions of the reference period. Journal of Experimental Criminology, 3, 39-64.

Marsick, V., \& Watkins, K. (2001). Informal and incidental learning. In S. Merriam (Ed.), New directions for adult and continuing education (pp. 24-34). San Francisco, CA: Jossey-Bass. Available at http://www2.wau.nl/psf/en/workshops/Informal\%20learning.pdf

Martin, E., \& Ramsden, P. (1987). Learning skills or skill in learning? In: J. T. E. Richardson, M. W. Eysenck, \& D. W. Piper (Eds.), Student learning research in education and cognitive psychology (pp. 155-167). Milton Keynes: Open University Press. 
Marton, F., Dall'Alba, G., \& Beaty, E. (1993). Conceptions of learning. International Journal of Educational Research, 19, 277-300.

Marton, F., \& Säljö, R. (1976). Qualitative differences in learning: 1. Outcome and process. British Journal of Educational Psychology, 46, 115-127.

Means, B., Toyama, Y., Murphy, R., Bakia, M., \& Jones, K. (2009). Evaluation of evidence-based practices in online learning: A meta-analysis and review of online learning studies. U.S. Department of Education, Office of Planning, Evaluation, and Policy Development, Washington, D.C. Retrieved, July $2^{\text {nd }}, 2009$, from http://www.ed.gov/rschstat/eval/tech/evidence-based-practices/finalreport.pdf

Olson, D. R., \& Bruner, J. S. (1996). Folk psychology and folk pedagogy. In D. R. Olson \& N. Torrance (Eds.), Handbook of education and human development: New models of learning, teaching, and schooling (pp. 9-27). Cambridge, MA: Blackwell. Available at http://people.uncw.edu/caropresoe/EDN500/chapter2.pdf

Rice, K., \& Dawley, L. (2009). The status of professional development for K-12 online teachers: Insights and implications. Journal of Technology and Teacher Education, 17, 523-545.

Rovai, A. P., Wighting, M. J., Baker, J. D., \& Grooms, L. D. (2009). Development of an instrument to measure perceived cognitive, affective, and psychomotor learning in traditional and virtual classroom higher education settings. The Internet and Higher Education, 12(1), 7-13.

Russell, T. L. (1999). The no significant difference phenomenon. Chapel Hill, NC: Office of Instructional Telecommunications, North Carolina State University.

Säljö, R. (1979). Learning in the learner's perspective: 1. Some common sense conceptions (Tech. Rep. No. 76). Göteborg, Sweden: University of Göteborg, Department of Education.

Skule, S. (2004). Learning conditions at work: A framework to understand and assess informal learning in the workplace. International Journal of Training and Development, 8(1), 8-17.

Straka, G. (2002). Valuing learning outcomes acquired in non-formal settings. In W. J. Nijhjof, A. Heikkinen, \& F. M. Nieuwenhuis (Eds.), Shaping flexibility in vocational education and training: Institutional, curricular and professional conditions (pp. 149-166). Boston: Kluwer Academic Publishers.

Zuzovsky, R., \& Donitsa-Schmidt, S. (2004). Attracting, developing and retaining effective teachers in Israel. OECD country background report. School of Education, Science and Technology Education Center, Tel-Aviv University. Retrieved December 22, 2008, from http://www.hakoled.org.il/webfiles/fck/teachers israel.pdf

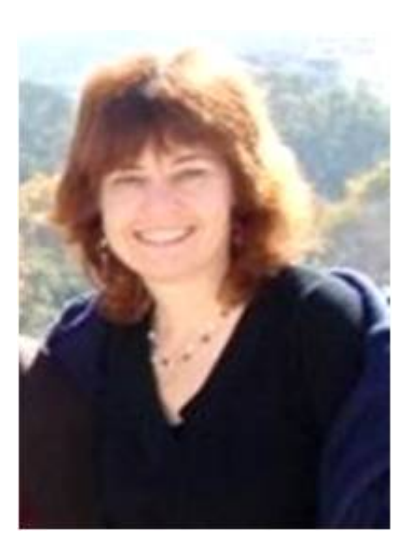

\section{Biographies}

Ariella Levenberg holds a B.A. in Humanities (Haifa University, Faculty of Education, and the Department of Fine Arts), and a M.A. in Learning Technologies and Networks (Open University of Israel, Department of Education \& Psychology). Her research interests include characteristics of Cyberculture and Cybergogy, social aspects of learning, as well as integration of social media in formal and informal learning. 


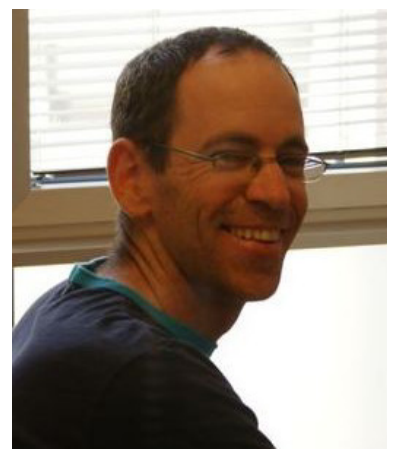

Avner Caspi is a faculty member at the Open University of Israel, Department of Education \& Psychology. He holds a B.A. in Behavioral Sciences (Tel-Aviv Yaffo Academic College), and Ph.D. in Cognitive Psychology (Tel Aviv University). His major research and publications interests focus on social aspects of communication technologies, mainly in the area of learning and instruction. Personal site: http://www.openu.ac.il/Personal_sites/avner-caspi.html 